\title{
A Study on Critical Care Obstetrics' in Eclampsia Patients-ICU Management and Maternal Outcome in Obstetrics and Gynaecology Department, Dhaka Medical College Hospital
}

\author{
Dr. Fowzia Yasmin ${ }^{*}$, Dr. Aklima Akter ${ }^{2}$, Dr. Farida Begum ${ }^{3}$ \\ ${ }^{1}$ Assistant Professor, Department of Gynecology and Obstetrics, Sir Salimullah Medical College \&Mitford Hospital, Dhaka, \\ Bangladesh \\ ${ }^{2}$ Assistant Professor, Department of Gynecology and Obstetrics, Sheikh Hasina Medical College, Tangail, Tangail, Bangladesh \\ ${ }^{3}$ Senior consultant, Department of Gynecology and Obstetrics, Sher E Bangla Medical College \& Hospital, Barishal, Bangladesh
}

DOI: 10.36348/sijog.2021.v04i04.001 $\quad$ | Received: 06.03.2021 | Accepted: 24.03.2021 | Published: 05.04.2021

*Corresponding author: Dr. Fowzia Yasmin

Abstract

Introduction: Eclampsia is a very serious and relatively frequent complication of pregnancy which is considered as 'obstetrical tragedy' to the unborn fetus the mother and to the obstetricians. Early diagnosis and proper treatment can reduce the maternal mortality due to eclampsia. Aim of the study: The aim of this study was to assess the maternal outcome of intensive care management for the critically ill eclamptic patients admitted in Dhaka medical college Hospital. Methods: This longitudinal prospective study was conducted in Eclampsia ward and ICU Ward of Dhaka medical college Hospital from January to December of 2004. Sixty Seven very critically ill eclampsia patients were included in this study. Relevant information regarding demographic, during pregnancy, complications, past history of eclampsia, history of antenatal check-up, including drug history were collected. Result: In this study among the 757 eclampsia patient, 67 (8.85\%) were critically ill. Maternal mortality was $43.11 \%$ due to eclampsia. $70 \%$ patients had very high diastolic blood pressure, $44.77 \%$ patients have severe oliguria, and $61.69 \%$ patients had severe degree of proteinuria. $26.86 \%$ of patient's level of consciousness was less than 5 . Unavailability of bed is the prime (75\%) cause of delay in shifting patient to ICU ward. Those treated by peritoneal dialysis recovered completely (100\%). $25.37 \%$ patients had HELLP syndrome and $20.89 \%$ had CVA. The most common cause of maternal death in eclampsia ward was cerebrovascular accident $31.42 \%$ and in ICU multiorgan failure $(33.33 \%)$. Mortality was very high among the patients who were with no ante-natal check-up $(82.23 \%)$. Twenty patients received ICU support and mortality is 12 (60\%), but among those 47 patients not received support mortality is 35 (75\%). Conclusion: Many patients come to the Hospital at the terminal stages, not only with primary complications but also with many secondary complications. Therefore, a last minute best management effort should be given to everyone by when the complications are diagnosed, a teamwork approaches by multidisciplinary health care.

Keywords: Eclampsia, Intensive Care Unit, Maternal Outcome, Obstetrics and Gynaecology.

Copyright (C) 2021 The Author(s): This is an open-access article distributed under the terms of the Creative Commons Attribution 4.0 International License (CC BY-NC 4.0) which permits unrestricted use, distribution, and reproduction in any medium for non-commercial use provided the original author and source are credited.

\section{INTRODUCTION}

Pregnancy complications such as-shock, coagulation disorders, thromboembolism and acute respiratory distress syndrome can lead to significant morbidity [1]. Eclampsia is a disease that is peculiar to the human species and significantly to the state of pregnancy. It is a major obstetrical emergency. Even Hippocrates around 500 BC knew about this treacherous and dreadful complication of pregnancy, but the word 'eclampsia' was not use until seventeenth century. The word eclampsia was first used in 1619 and is derived from the Greek word 'EKAMPECIN' means 'to shine forth' or 'flash-out' or 'like a flash or lightening' because of the unusual visual phenomena accompanying the convulsion [2]. Not surprisingly, only from 1910 onwards - routine measurement of blood pressure in pregnant woman including eclampsia was started [3]. A definition put forward for eclampsia states that 'Pre-eclampsia complicated with convulsions 
Fowzia Yasmin et al; Sch Int J Obstet Gynec, Apr. 2021; 4(4): 82-89

and or coma is called eclampsia'. Thus, it may occur in patients who have pre-eclampsia superimposed on essential hypertension on chronic nephritis [4]. Eclampsia is an 'obstetrical tragedy' to the unborn fetus, the mother and to the obstetricians, because the cause is not known, its onset is highly unpredictable and it has a train of life threatening complications, which often kills both the mother and the fetus, require 'critical' care obstetrics. The incidence of eclampsia is from $2-30 \%$ in developing countries [5]. Eclampsia is an important cause of both maternal and perinatal mortality and morbidity. In Dhaka Medical College Hospital total number of admitted patient in eclampsia ward in 2003 were 1069, among them maternal mortality was $40(3.74 \%)$ [6]. However, eclampsia is largely a preventable disease. This is proved beyond doubt as the incidence and mortality due to eclampsia has been reduced to $0.2-0.5 \%$ of all deliveries over the past five decades in the developed countries [7]. This is due to availability of routine antenatal care and improved socio-economic conditions and also availability of intensive care facility in management or eclampsia. Eclampsia is a multisystemic disease. The main cause of maternal mortality and morbidity are due to development of complications of eclampsia. So, early detection and treatment of the major complications is very part of management of eclampsia. Eclampsia occurs in patients with pre-eclampsia who have failed to receive regular antenatal care or in whom a relative sudden increase in blood pressure or the appearance of proteinuria has been overlooked. The onset of eclampsia is usually insidious and the patient often has minimum or no symptoms until she presents with eclamptic fits. Complications that usually occur arePulmonary edema-very common in eclampsia and HELLP (Hemolysis, Elevated liver enzyme enzymes and Low platelet count) syndrome [8]. Probable causes of maternal death in eclampsia are severe pulmonary edema, Cardiac failure, cerebral hemorrhage, Aspiration pneumonia, renal failure, Post-partum shock, Puimonary embolism, disseminated intra vascular coagulation, Hepatic rupture, and Puerperal sepsis [9]. Critical care obstetrics in eclampsia patients have a wide spectrum of research material. New lights are being focused on the subjects in developed countries, but very few studies have been carried out in our country. So, I felt the need of a study on critical care obstetrics in eclampsia patients ICU management and maternal outcome.

\section{OBJECTIVES}

General: To assess the maternal outcome of intensive care management (multidisciplinary approach) for the critically ill eclamptic patients admitted in Dhaka medical college Hospital.

\section{Specific}

- To find out the prevalence of complications developed in eclamptic patients, in Dhaka medical college Hospital.
- To detect types of complications in eclamptic patients.

- To determine emergence of intensive and advanced care //intensive care// critical care // multidisciplinary help offered to the eclamptic patients.

- To find out the associated factors responsible for developing critical problems in eclamptic patients

- Risk factors associated with patients.

- Delays in management of patients at various levels

- Pre- Hospital level

- Hospital level

\section{METHODOLOGY \& MATERIALS}

This longitudinal prospective study was conducted in Eclampsia ward and ICU Ward of Dhaka medical college Hospital from January to December of 2004 (one year). Sixty Seven very critically ill eclampsia patients admitted in Dhaka Medical college Hospital and transferred to intensive care unit (ICU) were selected for this study. A pre-designed questionnaire was used to collect the data. Relevant information was collected by direct interview of patients, relatives/ attendants and from medical records. After admission, full history, including duration of pregnancy, time and number of convulsions, duration of unconsciousness, or other complications, Past history of eclampsia, history of antenatal check-up, family history, socioeconomic status, past medical or surgical history, including drug history, taken from attendants. Examinations comprised of recording pulse, Blood pressure, Temperature, Anaemia, Jaundice, Oedema, level of consciousness, condition of Heart and Lung. State of respiration and Neurological examination. Some Laboratory investigations also documented immediately, to assess severity of complications and also to justify the indications of transferring to ICU, from Eclampsia ward. Bed side heat coagulation test, CBC including Platelet count, Renal function tests, Liver function tests, Serum uric acid, 24 hours total urinary protein, Serum electrolytes, Fibrin degradation products, Blood gas analysis. After detection of severity of illness, who needed intensive monitoring and ICU support referred to ICU after initial general and obstetric care? Those patients who did not get ICU support were treated in Eclampsia Ward. Informed consent from patients, or guardians of patients was taken. Ethical consent also taken from authority. All data were checked and edited after collection. Relevant data were compiled and presented by Tables and Graphs.

\section{RESULT}

In this study, out of 8501 obstetric patients admitted in Dhaka Medical College Hospital during the study period 2004, number of eclamptic patients were 757.So incidence of eclampsia were $8.91 \%$. Among the 757 eclampsia patients, 67 were critically ill. The 
Fowzia Yasmin et al; Sch Int J Obstet Gynec, Apr. 2021; 4(4): 82-89

incidence of critical illness due to eclampsia were 8.85\% (Table-I). Eclampsia related maternal mortality in Dhaka Medical College Hospital in 2004 were $43.11 \%$. Table-II shows $64.17 \%$ patients were primi para, $55.22 \%$ were antepartum eclampsia and $59.04 \%$ patients came from low socioeconomic conditions. $44.78 \%$ of patients had their first conception within one year of their marriage. $64.17 \%$ patients were very ill, having >11 convulsion before admission. Table-III shows that on admission clinical parameters of critically ill eclamptic patients, $59.70 \%$ patients had very high diastolic blood pressure, $44.77 \%$ patients have severe oliguria, and severe degree of proteinuria had $61.69 \%$ of patients. $26.86 \%$ of patients' level of consciousness was less than 5. Table-IV shows that $15(75 \%)$ patients transferred to ICU after 8 hours of their admission into hospital. Unavailability of bed is the prime $(75 \%)$ cause of delay in shifting patients to ICU ward. Around $63 \%$ severely ill eclampsia patients failed to avail ICU support due to unavailability of ICU beds. Table-V shows that all intensive support provided were available only in ICU ward, those treated by peritoneal dialysis recovered completely (100\%) (One patient received more than one facility). Table-VI shows that among the 67 severely ill eclampsia patients $25.37 \%$ patients were HELLP syndrome and $20.89 \%$ were CVA. Table-VII shows that the most common cause of maternal death in eclampsia ward was cerebrovascular accident $31.42 \%$ and in ICU multiorgan failure (33.33\%). Figure-1 shows that, out of 67 critically ill eclamptic patients, only $29.85 \%$ were transferred to ICU ward and received level best care. Figure-2 shows among all $(\mathrm{N}=38)$ patients shifted to ICU, due to obstetrics indications; eclampsia related patients were $62.63 \%$, during the study period. Figure-3 shows the pattern of checkup and maternal outcome in severely ill eclampsia patients. Mortality was very high among the patients who were with no ante-natal check-up (82.23\%). Figure-4 shows that out of 67 critically ill eclamptic patients, 20 patients received ICU support and mortality is 12 (60\%), but among those 47 patients not received support mortality is $35(75 \%)$. Figure-5 shows range of duration of staying in ICU was 2 days-16 days (average-6 days).

Table-I: Incidence of eclampsia during the study period

\begin{tabular}{|l|c|c|}
\hline Number of patients admitted & $\mathbf{n}$ & \% \\
\hline $\begin{array}{l}\text { Total number of eclampsia patients admitted } \\
(\mathrm{N}=8501)\end{array}$ & 757 & 8.91 \\
\hline Total number of critically ill patient (N=757) & 67 & 8.85 \\
\hline Death due to eclampsia (N=67) & 47 & $43.11 \%$ \\
\hline
\end{tabular}

Table-II: Comparison of sociodemography of critically ill eclampsia patients

\begin{tabular}{|c|c|c|c|}
\hline \multicolumn{2}{|c|}{ Characteristics } & $\mathbf{n}$ & $\%$ \\
\hline \multirow{2}{*}{ Maternal age } & Median & \multicolumn{2}{|c|}{21} \\
\hline & Range & \multicolumn{2}{|c|}{$17-34$} \\
\hline \multirow[t]{2}{*}{ Parity } & Primipara & 43 & $64.17 \%$ \\
\hline & Multipara & 24 & $35.82 \%$ \\
\hline \multirow[t]{3}{*}{ Varieties of eclampsia } & APE & 37 & $55.22 \%$ \\
\hline & PPE & 20 & $29.85 \%$ \\
\hline & IPE & 10 & $14.92 \%$ \\
\hline \multirow[t]{3}{*}{ Socioeconomic condition } & Upper & 5 & $7.46 \%$ \\
\hline & Middle & 22 & $32.83 \%$ \\
\hline & Lower & 40 & $59.70 \%$ \\
\hline \multirow{2}{*}{$\begin{array}{c}\text { Previous history of } \\
\text { eclampsia }\end{array}$} & Present & 6 & $8.95 \%$ \\
\hline & Absent & 61 & $91.04 \%$ \\
\hline \multirow[t]{5}{*}{ Time difference in years } & $0-1$ & 30 & $44.78 \%$ \\
\hline & $1-2$ & 23 & $34.32 \%$ \\
\hline & $2-3$ & 7 & $10.45 \%$ \\
\hline & $3-4$ & 4 & $5.97 \%$ \\
\hline & $>4$ & 3 & $4.48 \%$ \\
\hline \multirow[t]{3}{*}{ No of convulsions (fits) } & $1-5$ & 2 & $2.98 \%$ \\
\hline & $6-10$ & 22 & $32.83 \%$ \\
\hline & $>11$ & 43 & $64.17 \%$ \\
\hline
\end{tabular}


Fowzia Yasmin et al; Sch Int J Obstet Gynec, Apr. 2021; 4(4): 82-89

Table-III: Profile of critically ill eclamptic patients on admission ( $N=67)$

\begin{tabular}{|c|l|c|c|}
\hline \multicolumn{2}{|c|}{ Parameter } & $\mathbf{n}$ & \% \\
\hline Systolic blood pressure (mm of Hg) & $>170$ & 20 & $29.85 \%$ \\
\cline { 2 - 4 } & $150-170$ & 30 & $44.77 \%$ \\
\cline { 2 - 4 } & $<140$ & 17 & $25.37 \%$ \\
\hline Diastolic Blood pressure (mm of Hg) & $>120$ & 40 & $59.70 \%$ \\
\cline { 2 - 4 } & $100-120$ & 22 & $32.83 \%$ \\
\cline { 2 - 4 } & $<100$ & 5 & $7.46 \%$ \\
\hline Urine output (ml) & $<400$ & 30 & $44.77 \%$ \\
\cline { 2 - 4 } & $400-1000$ & 16 & $23.88 \%$ \\
\cline { 2 - 4 } & $>1000$ & 21 & $31.34 \%$ \\
\hline Respiratory rate (per minute) & $12-16$ & 17 & $25.37 \%$ \\
\cline { 2 - 4 } & $16-20$ & 28 & $41.79 \%$ \\
\cline { 2 - 4 } & $>20$ & 22 & $32.83 \%$ \\
\hline Proteinuria & + & 7 & $10.44 \%$ \\
\cline { 2 - 4 } & ++ & 41 & $13.43 \%$ \\
\cline { 2 - 4 } & +++ & 49 & $73.13 \%$ \\
\hline Patellar reflex & Present & 18 & $26.86 \%$ \\
\cline { 2 - 4 } & Absent & 26 & $38.80 \%$ \\
\hline \multirow{2}{*}{ Level of (score-GCS) } & $<5$ & $34.32 \%$ \\
\cline { 2 - 4 } & $5-10$ & & \\
\cline { 2 - 4 } & $>10$ & 18 & 23 \\
\hline
\end{tabular}

Table-IV

\begin{tabular}{|c|l|c|c|}
\hline \multicolumn{2}{|c|}{ Characteristics } & n & \% \\
\hline \multirow{4}{*}{ Time interval } & $<1$ hour & 1 & $5 \%$ \\
\cline { 2 - 4 } & $2-4$ hours & 2 & $10 \%$ \\
\cline { 2 - 4 } & $5-7$ hours & 2 & $10 \%$ \\
\cline { 2 - 4 } & $>8$ hours & 15 & $75 \%$ \\
\hline \multirow{3}{*}{$\begin{array}{c}\text { Cause of delay in shifting to } \\
\text { ICU from Eclampsia ward }\end{array}$} & Unavailability of ICU bed & 15 & $75 \%$ \\
\cline { 2 - 4 } & Lack of logistic support & 2 & $10 \%$ \\
\cline { 2 - 4 } & Lack of timely obstetric intervention & 2 & $10 \%$ \\
\cline { 2 - 4 } ICU support & Operational delay & 1 & $5 \%$ \\
\hline \multirow{3}{*}{\begin{tabular}{c} 
Cause of unavailability of \\
\cline { 2 - 3 }
\end{tabular}} & Unavailability of ICU bed & 30 & $63.83 \%$ \\
\cline { 2 - 4 } & Very severe illness (In a state of gasping) & 12 & $25.53 \%$ \\
\cline { 2 - 4 } & Lack of logistic support & 2 & $6.38 \%$ \\
\cline { 2 - 4 } & Lack of manpower & 0 & 0 \\
\cline { 2 - 4 } & Lack of decisions making & $26 \%$ \\
\hline
\end{tabular}

Table-V: Life support measures provide in ICU ( $N=20)$

\begin{tabular}{|l|l|l|}
\hline Variables & Number & Outcome \\
\hline Artificial nutrition and hydration & $2(10 \%)$ & $2(100 \%)$ \\
\hline Intravenous nutrition (Fluid \& electrolyte) & $20(100 \%)$ & \\
\hline Ventilatory support & $10(50 \%)$ & $5(50 \%)$ \\
\hline Cardiac monitoring & $10(50 \%)$ & $5(50 \%)$ \\
\hline Renal support: Peritoneal dialysis & $4(20 \%)$ & $4(20 \%)$ \\
\hline Neurological support (Neuro medicine) & $2(10 \%)$ & $1(50 \%)$ \\
\hline Physiotherapy and rehabilitation & $5(25 \%)$ & $5(100 \%)$ \\
\hline
\end{tabular}


Table-VI: Pattern of complications in critically ill eclampsia patients $(\mathrm{N}=67)$

\begin{tabular}{|l|l|l|}
\hline Complications & $\mathbf{n}$ & \% \\
\hline CVA (suspected) & 14 & $20.89 \%$ \\
\hline HELLP syndrome & 17 & $25.37 \%$ \\
\hline DIC & 4 & $5.97 \%$ \\
\hline Pulmonary complications & 13 & $19.40 \%$ \\
\hline Renal failure & 10 & $14.93 \%$ \\
\hline Multi organ failure & 9 & $13.43 \%$ \\
\hline
\end{tabular}

Table-VII: Final cause of maternal mortality $(\mathrm{N}=47)$

\begin{tabular}{|l|c|c|}
\hline Cause & $\begin{array}{c}\text { Eclampsia } \\
\text { ward }(\mathbf{n = 3 5})\end{array}$ & $\begin{array}{c}\text { ICU } \\
(\mathbf{n = 1 2})\end{array}$ \\
\hline Cerebrovascular accident & $11(31.42 \%)$ & $2(16.66 \%)$ \\
\hline HELLP syndrome & $5(14.28 \%)$ & $1(8.30 \%)$ \\
\hline Multiorgan failure & $6(17.14 \%)$ & $4(33.33 \%)$ \\
\hline DIC & $3(8.57 \%)$ & $1(8.3 \%)$ \\
\hline Pulmonary complications & $8(22.85 \%)$ & $4(33.33 \%)$ \\
\hline Septicaemia with hypoxic encephalopathy & $1(2.85 \%)$ & 00 \\
\hline Post partum shock & $1(2.85 \%)$ & 00 \\
\hline
\end{tabular}

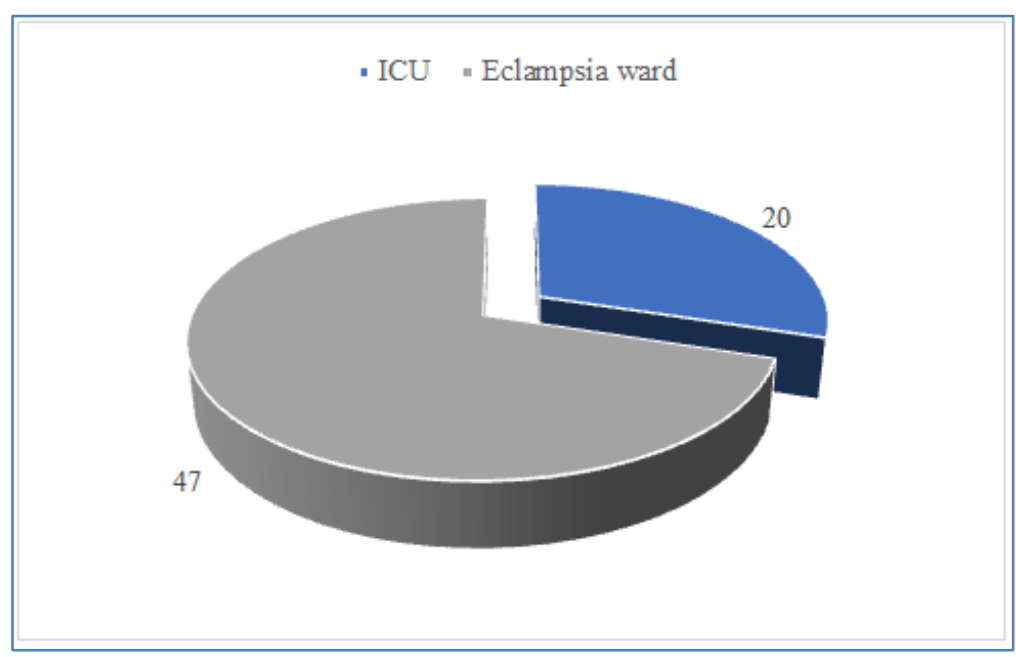

Fig-1: Distribution of critically ill patient $(\mathrm{N}=67)$

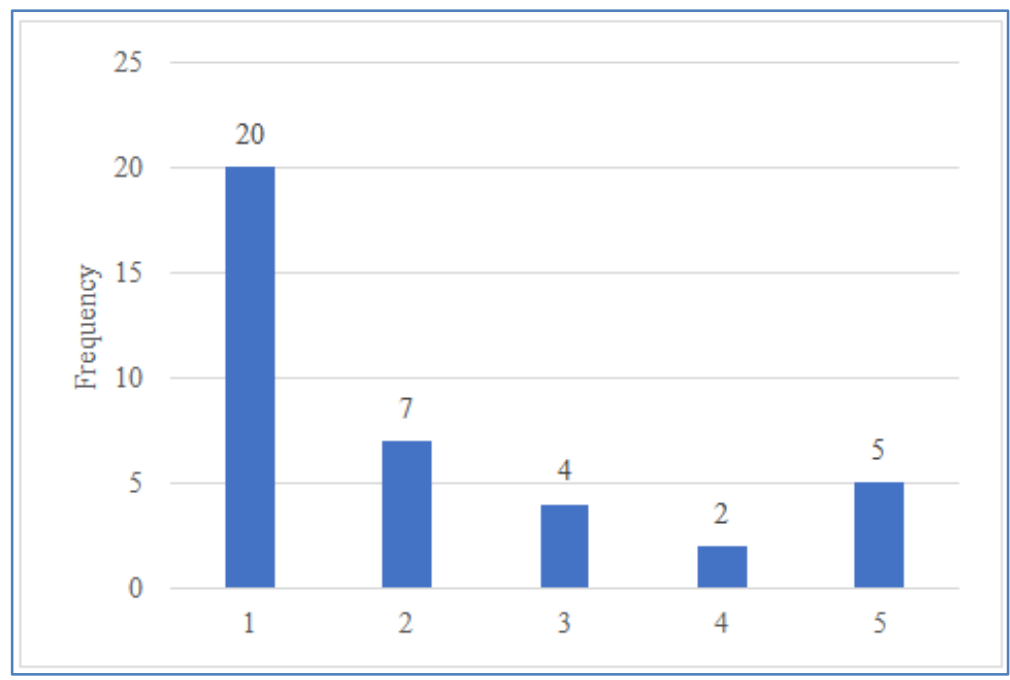

Fig-2: Obstetric indication of transferring to ICU ( $N=38)$ 


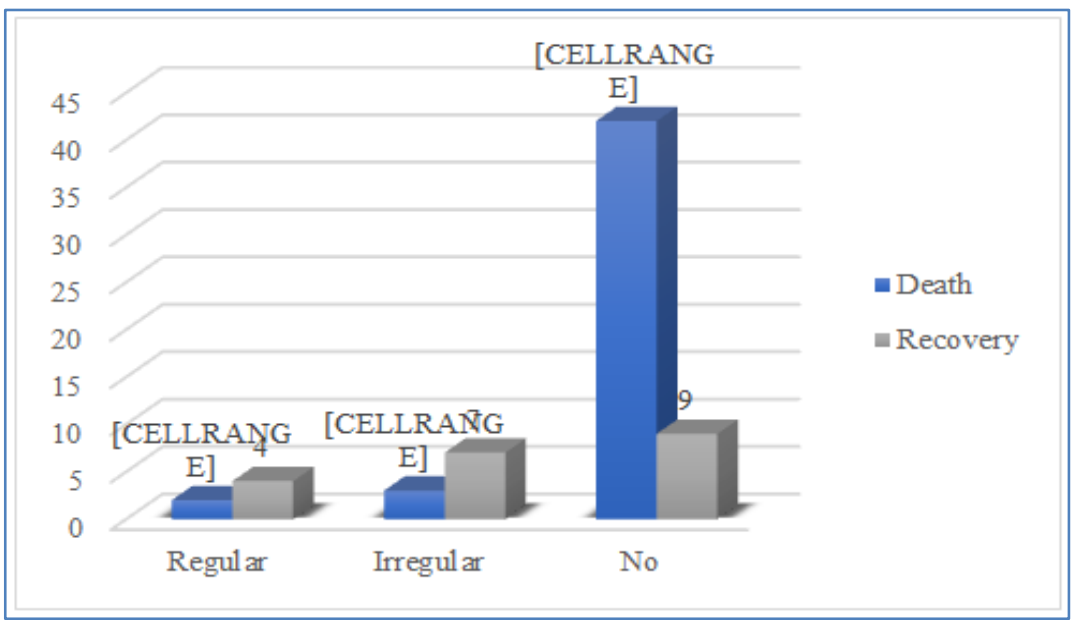

Fig-3: Distribution of antenatal checkup and maternal outcome in severely ill eclamptic patient

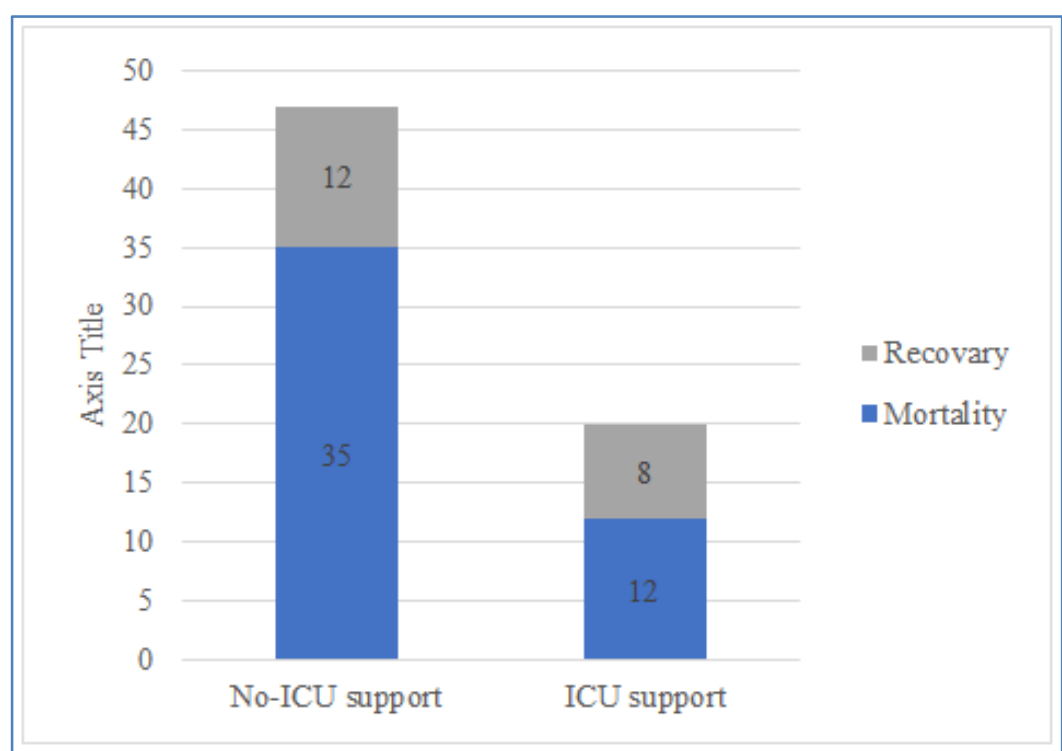

Fig-4: Comparison of maternal outcome between ICU support receivers and no receivers

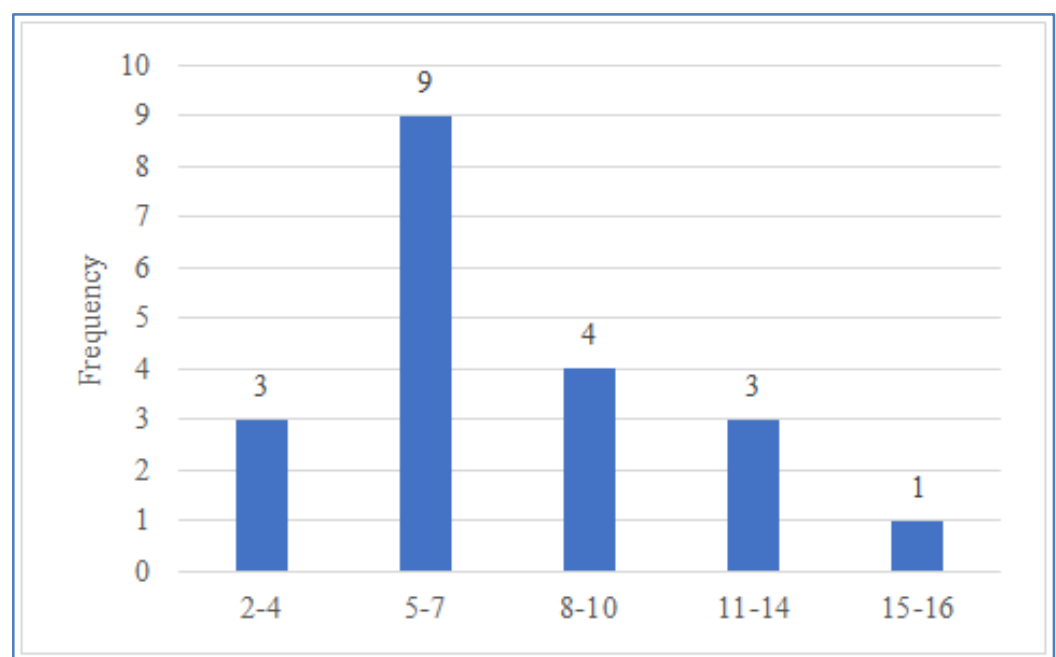

Fig-5: Distribution of staying in ICU of severely ill eclampsia patient $(\mathrm{N}=20)$

\section{DISCUSSION}

During the study period (2004), Total number of obstetrics patients admitted in Dhaka Medical
College Hospital were 9078, among them eclamptic patients were 757 , so, incidence of eclampsia was $8.91 \%$. Out of 757 Eclamptic patients, 67 were 
Fowzia Yasmin et al; Sch Int J Obstet Gynec, Apr. 2021; 4(4): 82-89

critically ill. So, incidence of critically ill eclamptic patients in 2004 were $8.85 \%$. Among the critically ill 67 eclamptic patients, 47 died. So, outcome of critically ill eclamptic patients were $70.14 \%$ mortality. In 2003, total number of patients admitted were 1069 among them maternal mortality were $40(9.35 \%)$. In this study, it is shown that, total maternal mortality of Dhaka Medical College Hospital in 2004, was 109, out of them eclampsia related mortality was $47,(43.11 \%)$ which was much higher than USA [10]. Hypertensive disorders of pregnancy accounts for approximately $15 \%$ of pregnancy related death, represented $2^{\text {nd }}$ leading cause of maternal mortality and morbidity in USA and first cause in Bangladesh. This finding is consistent with study of Okafor, -U- V, Aniebue,-U, Nigeria [11]. Current study revealed that only $29.85 \%$ critically ill patients received ICU support which is inconsistent to findings of Dao-B, Roumba,-A et al. France [12]. In their study $100 \%$ patients received ICU support, which needed it. The main cause of this inconsistency in Dhaka Medical College Hospital was due to lack of ICU bed and delay in reaching Hospital. This study showed major obstetric indication of transferring to ICU was eclampsia related Complications (52.63\%), which is similar to other studies, Balderas-penna et al. [13] From this study, it was revealed that primigravid, low socio-economic group of ante-partum eclampsia patients, with no previous history, were vulnerable to critical care obstetrics eclamptic patients. This study finding is accord with Afroz S [14]. Present study showed, on admission, clinical parameters of critically ill eclamptic patients were scored according to APACHE-II (Acute physiology And Chronic Health Evaluation), to identify risk patients or that patient who could benefit from intensive care unit treatment. This result was very much consistent to that of Ben- Letaifa$\mathrm{D}$ et al., Paris [15]. This study focused that, no antenatal check-up and irregular check-up has a relevancy with critical illness. This study is consistent with those of Rouf S, et al. [16]. In this study, it is seen that, $64.17 \%$ patients had $>10-11$ number of convulsions before admission into Hospital. This finding is almost similar to those findings of Begum $\mathrm{F}$ [10] and Rouf S. et al. [16]. This reflect about delay in seeking medical help in pre Hospital level, lack of minimum health education and poor socio economic status of our country. From this study, it was revealed that there was delay in shifting of critically ill patients from Eclampsia ward to ICU ward. $75 \%$ of those patients who transferred to ICU, shifted there, after $>8$ hours of their admission into Hospital. This study finding is not similar to other study finding [17, 12]. This study showed unavailability of bed was the major cause of delay in shifting to ICU. Lack of ICU bed, delay in reaching Hospital leading to gravious condition of patients were (70.14\%) important causes of deprivation from ICU support. In this study, it is shown that those patients who treated in ICU, mortality was $60 \%$ which is consistent with study of Dao- B, et al. (France) [12]. Regarding life supportive measure and invasive monitoring of critically ill patients in ICU, in addition to haemodynamic balance and nutrition maintenance, artificial ventilation, cardiac monitoring needed by $50 \%$ of patients which is not consistent to other international studies [15]. Neurological and renal support provided were similar to study of Ben-Letaifa,D [15]. Regarding pattern of complications in critically ill patients, HELLP syndrome (25.37\%), Neurological problems (cerebro-vascular accident) $(20.89 \%)$ and pulmonary complications were $(19.40 \%)$. These findings are similar to findings of Ben -L et al. [15] Tunisie. This study showed final causes of maternal mortality was multi system organ failure (MSOF) in ICU. Primary insult was HELLP syndrome. BalderasPena, et al. [13] showed similarities between HELLP syndrome and systemic inflammatory response syndrome (SIRS) because they could have the same patho-physiology. In ICU ward $33.33 \%$ death were due to MSOF, In Eclampsia ward major cause of death was cerebro-vascular accident $(31.42 \%)$. This study is similar to other studies by Balderas-P et al. [13] Spain. In a study in 2002, by Yasmin N [18], showed that maternal complications that were encountered, pulmonary edema occupy top of the list and then CVA, then renal failure. Among the pulmonary edema occupied top of the list in many other studies [19, 16]. In some studies, CVA was found to be the most common complication complications [20]. Out of 47, $(70.149 \%)$ maternal mortality, 15 (31.919\%) death were within one hour of admission into this hospital. These were very unfortunate group who delayed in receiving minimum management in pre hospital level, were delayed in referring into hospital. There are some underlying causes, for which patients are presented late, when death could not be prevented, even in high quality services provided in the eclampsia unit and modern ICU facilities. Some were not able to have ICU support due to their gravious condition and expired within a short period. Scoring system are used to predict outcome and evaluate care, they are validated and are widely used in ICUs. Analysis of mortality trend showed, death in ICU was delayed about 3 (three) days and they got level best care. Those treated in Eclampsia ward did not receive all supports they needed and faced an earlier death. In this study, it is shown that range of staying in ICU was 2-16 days and average was 6 days. This finding correlate with findings of other studies by Ben L et al. [15] Tunisie. The cause of eclampsia still remains elusive, but continued research provided hope with regard to screening, improved diagnosis and management.

\section{Limitations of the study}

Due to the moribund state of eclampsia patients and due to the lack of facilities the following investigations couldn't be done; -Magnetic resonant imaging (MRI) -CT scan of brain Sometimes attendants of some patients were unable to respond properly to the questionnaire, as they were not relative of the patients. As the study was confined to a very limited number of 
Fowzia Yasmin et al; Sch Int J Obstet Gynec, Apr. 2021; 4(4): 82-89

hospital patients, the conclusions may not reflect the truth in the community.

\section{CONCLUSION}

In this study, the focus was on ICU (intensive care unit) support provided in critically ill eclamptic patients, admitted in Dhaka medical college hospital and also who does not receive such support, in the same Hospital. Maternal outcome was guarded. Many patients come to the Hospital at the terminal stages, not only with primary complications but also with many secondary complications. They are delayed at every steps of their journey. Therefore, a last minute best management effort should be given to everyone by when the complications are diagnosed, a teamwork approaches by multidisciplinary health care. Round the clock quality nursing care by teamwork is an absolute necessity in the management of these patients. A vigilant eye must be kept during management of eclampsia patients who require critical care. A diverse group of highly trained professionals who provide care and work toward the best outcome possible. So, maternal mortality and morbidity related to eclampsia can be reduced. Intensive care unit (ICU) facilities should be more available for maternal health care. If we can afford ICU support earlier and more readily before they go to grave condition, we can save lots of our critically ill eclamptic mothers. In Dhaka medical college hospital ICU bed number is very inadequate, so availability of bed is very difficult. Trained medical personal should be appointed. Health education about the benefits of antenatal care and consequence of eclampsia should be given to concern by mass media. Ongoing research facilities in eclampsia care must be present.

\section{REFERENCES}

1. De Cherney, A.H., Nathan, L. (2002). Current Obstetric and Gynaecologic diagnosis and treatment. 9th ed. Medical publishing division, New York: Lange medical Books/ Mcgraw-Hil; P1041

2. Dorji, P., Kabir, Z., Akhter, S., \& Begum, M. R. (2000). Study of Renal function in eclampsia patients. The Journal of Obstetrics \& Gynaecology Research, 1, 11-189.

3. Nahar, S. (1996). HELLP syndrome in Eclampsia (A thesis: Bangabandhu Sheikh Mujib Medical University, Dhaka), 129

4. Dutta, D.C. (2001). Text Book of Obstetrics. 5h Ed. New central Book Agency: Calcutta; 35, 52,242

5. Edmonds, D.K. (2000). Dewhurst's Textbook of Obstetrics and Gynaecology for Postgraduates. 6th Ed. Blakwell Science Ltd: Osney Mead, Oxford, 2000. P.83, 87, 90, 92, 177, 182,186,187,209.

6. Eclampsia Ward statistics. (2003). Dhaka Medical College Hospital.
7. Arias, F. (2000). Practical guide to high risk pregnancy and delivery.2nd ed. Mosby - year book, USA.

8. Sultana, S. (2002). Disseminated intravascular coagulation a review article, Bangladesh College of Physicians and Surgeons, Dhaka, 44.

9. Rouf, S. (1991). Clinical Management of Eclampsia Patient admitted in Dhaka medical College Hospital by a New Protocol of regime- A study of hundred cases. Dissertation; Bangladesh College of Physicians and Surgeons, Dhaka, 3, 4, 26, 56, 58, 64, 94.

10. Begum, F. A study on management of Eclampsia (Dissertation) Dnakd. Bangladesh College of physicians and surgeons.

11. Okafor, U.V., Aniebue, U. (2004). Admission pattern and outcome in critical care obstetric patients, Department of anesthesia and Obstetrics and Gynecology. University of Nigeria Teaching Hospital Enugu, Nigeria: Int-J-Obstet-Anestn, 13(3): 164-6.

12. Yasmin, F., Rashid, M., \& Sultana, M. T. (2013). Emergence of Maternal Intensive Care Unit in Medical College Hospital. DinajpurMed Col $J, 6(1), 97-99$.

13. Balderas, P., Canales, M., J.L., Angulo, V., Anaya, P., Gonzalez, O. (2002). HELPP syndromeevidence of a possible systemic inflammatory response in pre-eclampsia: GinecolObstet-Mex, 70: 328-37

14. Afroz, S. (2004). Study on maternal and fetal outcome of Eclampsia in Mymensing Medical College Hospital; Dissertation. Bangladesh College of physicians and surgeons.

15. Ben, L., Daouas, N., Ben, J., Slama, A., Jegham, H. (2002). Maternal emergencies requiring controlled ventilation; epidemiology and prognosis: $J$ Gynacol-Obstet- Biol- reprod-(Paris), 31(3): P.256-60.

16. Rouf, S., Shamsuddin, L., Khan, J.H. (1996). Magnesium Sulphate versus diazepam in the management of Eclampsia, Bangladesh $J$ obstet gynaecol, $11 ; 1-14$.

17. Morghani, H.M., Hamed, M., Ezimokhi, M., Weerasinghe, D.S. (2004). Pregnancy related admission in the intensive care unit. Int-J-ObstetAnesth, 13(2): 85-2.

18. Yasmin, N. (2002). A critical analysis of cases of Eclampsia in Dhaka Medical College Hospital, Dissertation, Bangladesh College of physicians and surgeons.

19. Lelia, D. (1995). The must read Trial, Eclampsia, Lancet, July.17-26. 4

20. Aral. (2000). Clinical presentation of eclampsia in Dhaka Medical College Hospital- A study of 200 cases (Dissertation 92). Bangladesh College of Physicians and Surgeons. 